\title{
Protective effect of maifanite against cadmium-induced oxidative stress to rats hippocampus by regulating the balance and metabolism of metals
}

\author{
Hailin Liao, Lingfeng Jiang ${ }^{\#}$, Hongmiao Huang, Lixia Zhou, Ling Li, Shixian Cheng \\ Faculty of Pharmacy, Guangxi University of Chinese Medicine, Nanning, China; ${ }^{\#}$ Corresponding Author: jianglingfeng@126.com \\ Received 11 June 2013; revised 11 July 2013; accepted 1 August 2013 \\ Copyright (C) 2013 Hailin Liao et al. This is an open access article distributed under the Creative Commons Attribution License, \\ which permits unrestricted use, distribution, and reproduction in any medium, provided the original work is properly cited.
}

\begin{abstract}
In this paper, the author reported the effect of maifanite on the learning and memory of rats suffering $\mathrm{Cd}$ poisoning by step-down and stepthrough test, analyzed the content of MDA, MT, SOD, and GSH-PX in the hippocampus of rats respectively, and assayed the content of $\mathrm{Fe}, \mathrm{Cu}$, $\mathrm{Zn}, \mathrm{Mn}, \mathrm{Se}$, and $\mathrm{Cd}$ in the hippocampus of rats. In the step-down test, it is found that maifanite can reduce the number of electric shock, prolong step-down latency, and cut down error times when rats are exposed to $\mathrm{Cd} 24 \mathrm{~h}$. In the stepthrough test, maifanite can obviously prolong the latency of entering the dark cabin of rats suffering $\mathrm{Cd}$ poisoning. The exogenous $\mathrm{Cd}$ can lead to the decrease of SOD and GSH-Px activity and the increase of MDA and MT content. The alternation of maifanite and $\mathrm{Cd}$ by the gavage can significantly increase the SOD and GSH-PX activity as well as MT content, while lessening the MDA content. The accumulation of exogenous $\mathrm{Cd}$ in hippocampus causes the increase of $\mathrm{Zn}$, $\mathrm{Fe}, \mathrm{Mn}$, and $\mathrm{Cd}$ content, and the decrease of $\mathrm{Cu}$ and Se content. The intake of maifanite can regulate the imbalance of metals content and make its content near to the of level control group. The research shows that maifanite can improve the ability of learning and memory of rats suffering Cd poisoning, increase MT formation and lower hyperoxidative damage. Maifanite has the function of balancing the content of trace elements in rats suffering $\mathrm{Cd}$ poisoning, and meanwhile can alleviate the toxicity of $\mathrm{Cd}$ effectively.
\end{abstract}

${ }^{*}$ Conflict of interest: authors declare that there is no conflict of interest.
Keywords: Maifanite; Cd Toxicity; Oxidative Stress; Metallothionein; Trace Element

\section{INTRODUCTION}

$\mathrm{Cd}$ is listed by the US Environmental Protection Agency as one of 126 priority pollutants. Soluble Cd salts can accumulate and has a long biological half-life of 17 to 30 years in humans, in which the toxity exerts an effect on the kidney, liver and central nervous system etc. [1]. Its exposure is inevitable and may produce toxic effects in many organs and organ systems through binding to biological structures, accumulation in internal organs or induction of free radical production [2]. Therefore, how to clear the $\mathrm{Cd}$ accumulation in the body is an urgent and important mission. $\mathrm{Cd}$ may contribute to the initiation and promotion of neurodegenerative diseases like Alzheimer's disease or Parkinson's disease, and its accumulation can lead to disturbance of metal homeostasis in the brain [3]. Another important aspect of Cd toxicity is its interaction, often antagonistic, with essential elements. Vice versa, additional intake of the essential elements may have a beneficial influence on the distribution and toxic effects of Cd [2].

Maifanite is a granitoid silicate and has been used in many fields for a long time in East Asia countries such as China and Japan, and has proved to have no toxicity. There are more than 50 elements in maifanite mineral $[4,5]$. Both the loose porosity structure and the very small size on the surface are caused as a result of the long-term weathering and denudation. Therefore, many mineral elements are produced after the primary maifanite mineral is immersed into water. The major elements in the aqueous extract of maifanite are $\mathrm{K}, \mathrm{Na}, \mathrm{Ca}, \mathrm{Mg}, \mathrm{Zn}, \mathrm{Cu}, \mathrm{Fe}, \mathrm{Mn}$, and Se etc. [4,5]. The animal experiments demonstrated 
that maifanite possesses an obvious pharmacological effect on anti-aging, anti-fatigue, anti-hypoxia and so on, which may be related to mineral elements in maifanite $[5,6]$. In our previous study, we found that maifanite could improve the learning and memory, and the antioxidant abilities of Alzheimer's Disease rats. Maifanite had the potential prevention and treatment for Alzheimer's Disease [7].

In the present research, the authors study the effects of the aqueous extract of maifanite on learning and memory of rats suffering cadmium poisoning by step-down and step-through tests. The hippocampus is a major component of the brains of humans and other mammals, and it is also a component of the limbic system and plays a critical role in learning and memory etc. [8]. Therefore, the hippocampal levels of superoxide dismutase (SOD), glutathione peroxidase (GSH-Px), malon dialdehyde (MDA) and metallothionein (MT) were assayed in order to research if maifanite can improve the antioxidant abilities of rats suffering $\mathrm{Cd}$ poisoning. For clarifying the content change of trace elements, the hippocampus levels of Fe, $\mathrm{Cu}, \mathrm{Zn}, \mathrm{Mn}, \mathrm{Se}$, and $\mathrm{Cd}$ were determined by ICP-AES technique.

\section{EXPERIMENTAL}

\subsection{Reagents}

The maifanite was purchased from the Guifeng Maifanite Company in Guangxi Guiping City, China. The aqueous extract of maifanite was obtained as follows: 1) the $10 \mathrm{~g}$ of maifanite (100 no. mesh) was immersed into deionized water $(100 \mathrm{ml})$ for $30 \mathrm{~min}$ at room temperature, and then it was refluxed at $80^{\circ} \mathrm{C}$ for $60 \mathrm{~min}$. It was filtered to prepare the aqueous extract of maifanite, represented by the $\mathrm{MF}_{\text {high. }}$ 2) The $\mathrm{MF}_{\text {high }}$ was diluted by ten times and 100 times, respectively, represented by the $\mathrm{MF}_{\text {middle }}$ and $\mathrm{MF}_{\text {low }}$. Using ICP-AES, the element concentration $(\mu \mathrm{g} / \mathrm{ml})$ of the $\mathrm{MF}_{\text {high }}$ is determined, which is Fe 0.068 , $\mathrm{Cu}$ 0.022, Mn 0.049, Zn 0.037, Se 0.015, and Al 0.001.

The $\mathrm{CdCl}_{2}$ and other chemicals were of analytical reagent grade and obtained from Shanghai Chemical Reagent Corp. (China).

The test kits of MDA, SOD, and GSH-Px were all purchased from Nanjing Jiancheng Bioengineering Institute (China). The kit of MT was provided by the Shanghai Jingma Biological Science \& Technology Co., Ltd. (China).

\subsection{Animals and Groups}

Fifty healthy male Sprague-Dawley rats, weighed 300 $\pm 10 \mathrm{~g}$ at the beginning of the experiments, were used, provided by Lab Animal Central of Guangxi Medical University. They were maintained under a 12/12-h light- dark cycle (light beginning at 8:00 a.m.) and in a controlled temperature $\left(22 \pm 2^{\circ} \mathrm{C}\right)$, relative humidity of $(60 \pm$ 10) percentage. They had access to food and deionized water. Animals were given an adaptive phase of one week to the lab condition. The study was approved by the Ethics Committee of Guangxi University of Chinese Medicine.

The rats were randomly divided into five groups. Each group consisted of ten animals, and each animal was used once: [A] control group: The $3 \mathrm{ml}$ saline solution was given by oral gavage, once daily for 30 days; [B] $\mathrm{CdCl}_{2}$ group: The $3 \mathrm{ml}$ saline solution first, and on the following day $10 \mu \mathrm{mol} / \mathrm{kg} \mathrm{CdCl} \mathrm{Cl}_{2}$ was given by gavage alternately, each for 15 days; [C] $\mathrm{CdCl}_{2}+\mathrm{MF}_{\text {low }}$ group: The 3 $\mathrm{ml} \mathrm{MF}_{\text {low }}$ first, and on the following day $10 \mu \mathrm{mol} / \mathrm{kg}$ $\mathrm{CdCl}_{2}$ was given by gavage alternately, each for 15 days; [D] $\mathrm{CdCl}_{2}+\mathrm{MF}_{\text {middle }}$ group: The $3 \mathrm{ml} \mathrm{MF}$ middle first, and on the following day $10 \mu \mathrm{mol} / \mathrm{kg} \mathrm{CdCl} \mathrm{Cl}_{2}$ was given by gavage alternately, each for 15 days; [E] $\mathrm{CdCl}_{2}+\mathrm{MF}_{\text {high }}$ group: The $3 \mathrm{ml} \mathrm{MF}$ high first, and on the following day 10 $\mu \mathrm{mol} / \mathrm{kg} \mathrm{CdCl} \mathrm{Cl}_{2}$ was given by gavage alternately, each for 15 days.

\subsection{Behavior Tests [9]}

After 30 days, behavior tests, including step-down test and step-through test, were carried.

Step-down test: After 30 days, the rats were tested by a step-down test in a passive avoidance chamber. The floor of the chamber consists of copper rods and a well-insulated platform made of rubber in one corner of the chamber. The rats were placed in the chamber for a 3-min adaptation period and were then placed on the platform. Their latency to step down on the grid with all four paws was measured. Upon stepping down on the copper bars, the rats received an immediate mild electrical shock (36 V). To avoid the shock, rats demonstrated an instinctive reaction to jump back onto the platform. Rats were tested in this manner for $5 \mathrm{~min}$. The number of times rats stepped down from the platform within 5 min was considered acquisition errors. After $24 \mathrm{~h}$, this procedure was repeated, and the step-down latency was used as a measurement of memory retention. The number of times the rats stepped down onto the platform within the 3-min interval was recorded as retention errors.

Step-through test: a step-through-type passive avoidance test was carried out to evaluate the effect of maifanite on learning and memory. The shuttle box $(60 \times 50 \times$ $80 \mathrm{~cm})$ consisted of two compartments of equal size $(20$ $\times 12 \times 60 \mathrm{~cm})$. Each compartment was divided into a light and a dark chamber by a guillotine door $(3 \times 4 \mathrm{~cm})$. The light chamber was equipped with an illuminator. All the rats were habituated to the light and dark chamber three times for 3 min until they entered the dark compartment within $15 \mathrm{~s}$ (training trial). The rats that did not 
enter the dark compartment within $15 \mathrm{~s}$ after the three habituations would be rejected. The test consisted of acquisition and retention sessions carried out 24 and $48 \mathrm{~h}$, respectively, after the training trial. For the acquisition trial, the rats were placed in the illuminated chamber opposite the guillotine door and allowed to move freely. When all four paws were on the grid floor of the dark compartment, a scrambled constant-current foot shock (constant voltage $50 \mathrm{~V}$ ) was delivered to the grid. The number of times the rats stepped into the dark chamber, the time spent in the dark chamber, and latency to move into the dark chamber within 5 min were recorded automatically by computer. $24 \mathrm{~h}$ after the acquisition trial, the rats were again placed in the light chamber for the retention trial. If a mouse did not enter the dark chamber within $300 \mathrm{~s}$, the latency was recorded as the cutoff time of $300 \mathrm{~s}$. Rats were removed manually from the light chamber when the cutoff time was reached.

\subsection{Lipid Peroxidation, SOD, GSH-Px and MT Analyses}

After the behavioral tests, the rats were sacrificed, and brains were quickly removed, followed by dissection of the hippocampus on ice. In order to determine the level of MDA, MT, SOD, and GSH-Px the four random rats hippocampus was weighed and homogenized with a buffer consisting of $10 \mathrm{mM}$ sucrose, $10 \mathrm{mM}$ Tris- $\mathrm{HCl}$, and $0.1 \mathrm{mM}$ EDTA ( $\mathrm{pH}$ 7.4) and then the homogenate was centrifuged at $3000 \mathrm{rpm}$ for $10 \mathrm{~min}$ at $4^{\circ} \mathrm{C}$. The supernatant was used for bioassays.

The contents of MDA and MT, and the activities of SOD and GSH-Px were assayed strictly according to the detection kit specification. The SOD activity MDA content was determined by hydroxylamine assay-developed from xanthine oxidase assay. The assay of GSH-Px activity and MDA content was determined by colorimetry.

\subsection{Metal Elements Analysis}

To transfer the hippocampus into liquid in order to measure metal elements concentration by the inductively coupled plasma-atomic emission spectroscopy (ICP-AES; IRIS Intrepid II XSP, USA Thermo Elemental), a microwave sample preparation system (MD6, Beijing Haotianhui trade Ltd. Corp.) was used. First, the hippocampus (1000 mg, wet weight) was mixed with $2 \mathrm{~mL}$ of $10 \%$ hydrogen nitrate and $1 \mathrm{ml}$ of $30 \%$ hydrogen peroxide. They then were put into the microwave oven for wet digesting for about $1 \mathrm{~h}$, after which we obtained the liquid. By ICP-AES, the elements $\mathrm{Fe}, \mathrm{Cu}, \mathrm{Zn}, \mathrm{Mn}, \mathrm{Se}$, and $\mathrm{Al}$ in the hippocampus of rats were analyzed. The conditions were $1200 \mathrm{~W}$ from the radio-frequency generator, a plasma argon flow rate of $15 \mathrm{~L} / \mathrm{min}$, a cooling gas flow of $14 \mathrm{~L} /$ min, a carrier gas flow of $1.0 \mathrm{~L} / \mathrm{min}$, a $20-\mu \mathrm{m}$ entrance slit, a $30-\mu \mathrm{m}$ exit slit, a height of observation of $15 \mathrm{~mm}$, and an integration time lapse of $5 \mathrm{~s}$.

\subsection{Statistical Analysis}

All statistical analysis was performed using SPSS statistical software package version 13.0. Data were expressed as mean \pm SD. One-way analysis of variance and LSD test were used for the tests between two or more groups. A p value less than 0.05 was considered to be statistically significant.

\section{RESULTS}

\subsection{Step-Down Test}

Performance of the rats in the step-down test is shown in Table 1. The number of electric shocks in $5 \mathrm{~min}$ increased ( $\mathrm{P}$ less than 0.01), and the step-down latency shortened ( $\mathrm{P}$ less than 0.01) $24 \mathrm{~h}$ later in $\mathrm{CdCl}_{2}$ group, as compared with control group. The shorter step-down latency and increased errors were reversed by increasing the concentrations of maifanite. The number of electric shocks in 5 min decreased (Pless than 0.05), the stepdown latency prolonged (P less than 0.05) $24 \mathrm{~h}$ later in $\mathrm{CdCl}_{2}+\left(\mathrm{MF}_{\text {high }}, \mathrm{MF}_{\text {middle }}\right.$ and $\left.\mathrm{MF}_{\text {low }}\right)$ group, as compared with $\mathrm{CdCl}_{2}$ group.

\subsection{Step-Through Test}

The result of step-through test of the rats is shown in Table 2. The first latency and the latency $24 \mathrm{~h}$ later shortened (P less than 0.01), the number of electric shocks in $5 \mathrm{~min} 24 \mathrm{~h}$ later increased (P less than 0.01 ) in $\mathrm{CdCl}_{2}$ group, as compared with control group. The shorter stepthrough latency and increased number of electric shocks were reversed by increasing the concentrations of maifanite. The first latency and the latency $24 \mathrm{~h}$ later prolonged (P less than 0.05), the number of electric shocks in 5 min $24 \mathrm{~h}$ later decreased (P less than 0.05$)$ in $\mathrm{CdCl}_{2}+\left(\mathrm{MF}_{\text {high }}\right.$, $\mathrm{MF}_{\text {middle }}, \mathrm{MF}_{\text {low }}$ ) group, as compared with $\mathrm{CdCl}_{2}$ group.

Table 1. Results of step-down test (mean $\pm \mathrm{SD}, \mathrm{n}=10$ ).

\begin{tabular}{|c|c|c|c|c|}
\hline \multirow[b]{2}{*}{ Group } & \multirow{2}{*}{$\begin{array}{c}\text { Number of } \\
\text { electric shocks } \\
\text { in } 5 \min (\mathrm{n})\end{array}$} & \multicolumn{3}{|c|}{ After $24 \mathrm{~h}$} \\
\hline & & $\begin{array}{c}\text { Rats number } \\
\text { of electric } \\
\text { shocks (n) }\end{array}$ & $\begin{array}{l}\text { Step-down } \\
\text { latency (s) }\end{array}$ & $\begin{array}{l}\text { Number of } \\
\text { errors in } 3 \\
\min (\mathrm{n})\end{array}$ \\
\hline$[\mathrm{A}]$ & $0.9 \pm 0.6$ & 8 & $16 \pm 9.7$ & 7 \\
\hline$[\mathrm{B}]$ & $1.3 \pm 0.8^{1)}$ & 9 & $11 \pm 14.9^{1)}$ & 9 \\
\hline$[\mathrm{C}]$ & $0.8 \pm 0.5^{2)}$ & 7 & $61 \pm 35.6^{2)}$ & 6 \\
\hline [D] & $0.7 \pm 0.6^{2)}$ & 5 & $72 \pm 25.7^{2)}$ & 4 \\
\hline$[\mathrm{E}]$ & $0.5 \pm 0.6^{2)}$ & 3 & $95 \pm 35.3^{2)}$ & 1 \\
\hline
\end{tabular}

[A]: control group, [B]: $\mathrm{CdCl}_{2}$ group, [C]: $\mathrm{CdCl}_{2}+\mathrm{MF}_{\text {low }}$ group, [D]: $\mathrm{CdCl}_{2}$ $+\mathrm{MF}_{\text {middle }}$ group. [E]: $\mathrm{CdCl}_{2}+\mathrm{MF}_{\text {high }}$ group. ${ }^{1)} \mathrm{P}$ less than 0.01 , significantly different from the control group. ${ }^{2} \mathrm{P}$ less than 0.05 , significantly different from the $\mathrm{CdCl}_{2}$ group. 
Table 2. Results of step-through test (mean $\pm \mathrm{SD}, \mathrm{n}=10$ ).

\begin{tabular}{ccccc}
\hline & & \multicolumn{3}{c}{ After 24 h } \\
\cline { 3 - 5 } Group & $\begin{array}{c}\text { First latency } \\
(\mathrm{s})\end{array}$ & $\begin{array}{c}\text { Latency } \\
(\mathrm{s})\end{array}$ & $\begin{array}{c}\text { Number of } \\
\text { electric shocks } \\
\text { in 5 min (n) }\end{array}$ & $\begin{array}{c}\text { Rats number } \\
\text { of entering } \\
\text { dark cabin in } \\
5 \text { min (n) }\end{array}$ \\
\hline [A] & $21.1 \pm 11.2$ & $30.2 \pm 15.3$ & $6.5 \pm 1.7$ & 10 \\
{$[\mathrm{~B}]$} & $13.1 \pm 10.5^{1)}$ & $22.6 \pm 18.3^{1)}$ & $7.8 \pm 2.4^{1)}$ & 10 \\
{$[\mathrm{C}]$} & $29.5 \pm 18.5^{2)}$ & $66.8 \pm 18.9^{2)}$ & $4.9 \pm 2.1^{2)}$ & 10 \\
{$[\mathrm{D}]$} & $48.3 \pm 26.4^{2)}$ & $89.4 \pm 15.2^{2,3)}$ & $3.5 \pm 1.9^{2,3)}$ & 10 \\
{$[\mathrm{E}]$} & $77.8 \pm 31.7^{2)}$ & $125.9 \pm 49.7^{2)}$ & $2.2 \pm 1.7^{2)}$ & 10 \\
\hline
\end{tabular}

[A]: control group, [B]: $\mathrm{CdCl}_{2}$ group, [C]: $\mathrm{CdCl}_{2}+\mathrm{MF}_{\text {low }}$ group, [D]: $\mathrm{CdCl}_{2}$ $+\mathrm{MF}_{\text {middle }}$ group. [E]: $\mathrm{CdCl}_{2}+\mathrm{MF}_{\text {high }}$ group. ${ }^{1)} \mathrm{P}$ less than 0.01 , significantly different from $[\mathrm{A}] .{ }^{2)} \mathrm{P}$ less than 0.05 , significantly different from $[\mathrm{B}] .{ }^{3)} \mathrm{P}$ more than 0.05 , no significant difference from $[\mathrm{C}]$.

There was no significant difference between $\mathrm{CdCl}_{2}+$ $\mathrm{MF}_{\text {low }}$ group and $\mathrm{CdCl}_{2}+\mathrm{MF}_{\text {middle }}$ group ( $\mathrm{P}$ more than $0.05)$.

\subsection{Biochemical Markers of Oxidative Stress in Hippocampus}

The activities of SOD and GSH-Px decreased in $\mathrm{CdCl}_{2}$ group, as compared with control group, but the levels of MDA and MT increased (P less than 0.01). The activities of SOD and GSH-Px, the level of MT in $\mathrm{CdCl}_{2}+\left(\mathrm{MF}_{\text {high }}\right.$, $\mathrm{MF}_{\text {middle, }}, \mathrm{MF}_{\text {low }}$ ) group increased markedly compared with those of $\mathrm{CdCl}_{2}$ group, while the content of MDA decreased (P less than 0.05; Table 3).

\subsection{Element Analysis in Hippocampus}

The hippocampus levels of $\mathrm{Fe}, \mathrm{Cu}, \mathrm{Zn}, \mathrm{Mn}, \mathrm{Se}$, and $\mathrm{Cd}$ of different groups are shown in Table 4. The levels of $\mathrm{Zn}, \mathrm{Mn}$ and $\mathrm{Cd}$ were higher ( $\mathrm{P}$ less than 0.01) in $\mathrm{CdCl}_{2}$ group, $\mathrm{CdCl}_{2}+\mathrm{MF}_{\text {low }}$ group, $\mathrm{CdCl}_{2}+\mathrm{MF}_{\text {middle }}$ group and $\mathrm{CdCl}_{2}+\mathrm{MF}_{\text {high }}$ group, as compared with control group. The levels of $\mathrm{Fe}, \mathrm{Cu}$ and $\mathrm{Se}$ were lower ( $\mathrm{P}$ less than 0.01) in $\mathrm{CdCl}_{2}$ group, $\mathrm{CdCl}_{2}+\mathrm{MF}_{\text {low }}$ group, $\mathrm{CdCl}_{2}+\mathrm{MF}_{\text {middle }}$ group and $\mathrm{CdCl}_{2}+\mathrm{MF}_{\text {high }}$ group, as compared with control group. The imbalance levels of $\mathrm{Fe}$, $\mathrm{Cu}, \mathrm{Zn}, \mathrm{Mn}, \mathrm{Se}$ and $\mathrm{Cd}$ were regulated with the increase of concentrations of maifanite near to the level of the control group. The levels of $\mathrm{Zn}, \mathrm{Fe}, \mathrm{Mn}$ and $\mathrm{Cd}$ in $\mathrm{CdCl}_{2}$ $+\left(\mathrm{MF}_{\text {high, }}, \mathrm{MF}_{\text {middle }}, \mathrm{MF}_{\text {low }}\right)$ maifanite group decreased markedly, as compared with $\mathrm{CdCl}_{2}$ group, meanwhile the level of $\mathrm{Cu}$ and Se were increased (P less than 0.05).

\section{DISCUSSION}

The results of step-down and step-through test showed that rats suffering cadmium poisoning may suffer the impairment of learning and memory. The results of the oxidative stress assay showed that $\mathrm{Cd}$ exposure could lead
Table 3. Activities of SOD and GSH-Px, Content of MDA and $\mathrm{MT}$ in hippocampus of rats (mean $\pm \mathrm{SD}, \mathrm{n}=10$ ).

\begin{tabular}{ccccc}
\hline Group & $\begin{array}{c}\text { SOD } \\
\text { (U/mg prot) }\end{array}$ & $\begin{array}{c}\text { GSH-Px } \\
\text { (U/mg prot) }\end{array}$ & $\begin{array}{c}\text { MDA } \\
\text { (pmol/mg } \\
\text { prot) }\end{array}$ & $\begin{array}{c}\text { MT } \\
\text { (pmol/mg prot) }\end{array}$ \\
\hline [A] & $84.6 \pm 10.5$ & $73.6 \pm 11.7$ & $4.7 \pm 1.4$ & $9.5 \pm 2.4$ \\
[B] & $67.6 \pm 19.8^{1)}$ & $56.7 \pm 15.7^{1)}$ & $7.1 \pm 1.3^{1)}$ & $15.8 \pm 3.6^{1)}$ \\
[C] & $103.1 \pm 12.6^{2)}$ & $110.41 \pm 16.7^{2)}$ & $4.0 \pm 1.2^{2)}$ & $20.2 \pm 12.6^{2)}$ \\
[D] & $158.2 \pm 8.2^{2)}$ & $149.9 \pm 18.9^{2)}$ & $3.3 \pm 2.1^{2)}$ & $23.2 \pm 20.2^{2)}$ \\
[E] & $201.4 \pm 5.7^{2)}$ & $178.6 \pm 19.4^{2)}$ & $2.6 \pm 1.8^{2)}$ & $29.8 \pm 15.9^{2)}$ \\
\hline
\end{tabular}

[A]: control group, [B]: $\mathrm{CdCl}_{2}$ group, [C]: $\mathrm{CdCl}_{2}+\mathrm{MF}_{\text {low }}$ group, [D]: $\mathrm{CdCl}_{2}$ $+\mathrm{MF}_{\text {middle }}$ group. [E]: $\mathrm{CdCl}_{2}+\mathrm{MF}_{\text {high }}$ group. ${ }^{1)} \mathrm{P}$ less than 0.01 , significantly different from $[\mathrm{A}] .{ }^{2} \mathrm{P}$ less than 0.05 , significantly different from $[\mathrm{B}]$.

to the decrease of SOD and GSH-Px activities, the increase of MDA content in rats' hippocampus. This further indicated that the mechanism of Cd toxicity may be oxidative stress [10]. For scavenging and reducing the toxic effects of $\mathrm{Cd}$, the animal tissues have another antioxidant-metallothioneins (MT), which selectively bound heavy metal $\mathrm{Cd}_{2}+$ ions entered in body, preserved, fixed and detoxified the ionic heavy metals [11]. The results show that $\mathrm{Cd}$ exposure can cause more MT formation. The exogenous Cd can induce MT formation in body [12]. Both constitutive and inducible MT are responsible for the detoxication of $\mathrm{Cd}$ [13]. Though the content of MT in $\mathrm{CdCl}_{2}$ group is more two times higher in hippocampus than that in control group, meanwhile the activities of SOD and GSH-Px is lower, and the content of MDA is higher. Those results indicate that there is a dysequilibrium between the production and clearance of free radicals after $\mathrm{Cd}$ exposure. The free radicals can not be cleared effectively, which may be the reason of the impairment of learning and memory. SOD exists mainly in two forms: $\mathrm{Cu} / \mathrm{ZnSOD}$ is present primarily in the cytoplasm while MnSOD is present primarily in the mitochondria [14]. Se is a cofactor of GSH-Px, and Secysteine is the active centre of GSH-Px, there is a direct relationship between Se and GSH-Px activity [15]. The present research results showed that the accumulation of $\mathrm{Cd}$ in hippocampus could lead to a disturbance of trace elements homeostasis. The homeostasis disturbances of $\mathrm{Cu}, \mathrm{Zn}$ and $\mathrm{Mn}$ weaken the physiological function of SOD, meanwhile, the decrease of Se restrains GSH-Px to take effect. The intake of maifanite can promote the imbalance of trace elements in rats suffering cadmium poisoning to reach near balance state, which is helpful to increase the activities of SOD and GSH-Px. Sequentially, the free radicals can be effectively eliminated; oxidation effect be weakened and MDA level be reduced. MT level can be induced by $\mathrm{Cd}$ as well as $\mathrm{Cu}$ and $\mathrm{Zn}$. The MT level in $\mathrm{CdCl}_{2}+$ $\left(\mathrm{MF}_{\text {high }}, \mathrm{MF}_{\text {middle }}, \mathrm{MF}_{\text {low }}\right)$ group is higher than that in 
Table 4. Results of elementary analysis in hippocampus of rats (mean $\pm \mathrm{SD}, \mathrm{n}=10)$.

\begin{tabular}{cccccc}
\hline \multirow{2}{*}{$\begin{array}{c}\text { Element } \\
(\mu \mathrm{g} / \mathrm{g} \text { wet weight })\end{array}$} & {$[\mathrm{A}]$} & {$[\mathrm{B}]$} & {$[\mathrm{C}]$} & {$[\mathrm{D}]$} & {$[\mathrm{E}]$} \\
\hline $\mathrm{nyyyy}$ & $43.35 \pm 8.13$ & $11.07 \pm 5.29^{1)}$ & $20.20 \pm 9.14^{2)}$ & $27.05 \pm 8.64^{2)}$ & $39.57 \pm 39.16^{2)}$ \\
$\mathrm{Fe}$ & $1.66 \pm 0.73$ & $0.34 \pm 0.37^{1)}$ & $0.77 \pm 0.59^{2)}$ & $1.38 \pm 0.49^{2)}$ & $1.69 \pm 1.01^{2)}$ \\
$\mathrm{Zn}$ & $25.69 \pm 4.99$ & $41.61 \pm 2.62^{1)}$ & $37.79 \pm 6.87^{2)}$ & $29.38 \pm 9.69^{2,3)}$ & $27.99 \pm 11.12^{2)}$ \\
$\mathrm{Mn}$ & $1.67 \pm 0.66$ & $2.99 \pm 0.52^{1)}$ & $2.38 \pm 0.57^{2)}$ & $1.93 \pm 0.45^{2,3)}$ & $1.71 \pm 0.89^{2)}$ \\
$\mathrm{Se}$ & $0.19 \pm 0.11$ & $0.03 \pm 0.05^{1)}$ & $0.09 \pm 0.13^{2)}$ & $0.14 \pm 0.05^{2,3)}$ & $0.25 \pm 0.05^{2)}$ \\
$\mathrm{Cd}$ & $0.09 \pm 0.05$ & $1.51 \pm 2.16^{1)}$ & $1.12 \pm 2.47^{2)}$ & $0.48 \pm 1.97^{2)}$ & $0.14 \pm 0.11^{2)}$ \\
\hline
\end{tabular}

[A]: control group, [B]: $\mathrm{CdCl}_{2}$ group, [C]: $\mathrm{CdCl}_{2}+\mathrm{MF}_{\text {low }}$ group, [D]: $\mathrm{CdCl}_{2}+\mathrm{MF}_{\text {middle }}$ group. [E]: $\mathrm{CdCl}_{2}+\mathrm{MF}_{\text {high }}$ group. ${ }^{1)} \mathrm{P}$ less than 0.01 , significantly different from $[\mathrm{A}] .{ }^{2)} \mathrm{P}$ less than 0.05 , significantly different from $[\mathrm{B}] .{ }^{3)} \mathrm{P}$ more than 0.05 , no significant difference from [C].

$\mathrm{CdCl}_{2}$ group. Generally, the induction of MT to bind $\mathrm{Cd}$ is considered a protective response of cells to the presence of this toxic metal. The increase of MT is beneficial to eliminate the toxicity of $\mathrm{Cd}[16]$. The larger the level of MT is, the stronger the eliminating effect is.

The results of ICP-AES show that microelements such as $\mathrm{Fe}, \mathrm{Zn}, \mathrm{Mn}, \mathrm{Se}$, and $\mathrm{Cu}$ play an important role in metabolic pathways affected by $\mathrm{Cd}$. Cd accumulates mainly in liver and kidney of animals [17]. The present research results showed that $\mathrm{Cd}$ could also accumulate in hippocampus. The $\mathrm{Cd}$ level increased more dramatically in $\mathrm{CdCl}_{2}$ group than that in control group. Compared to control group, the hippocampal levels of $\mathrm{Fe}, \mathrm{Se}$ and $\mathrm{Cu}$ in $\mathrm{CdCl}_{2}$ group decreased, and those of $\mathrm{Zn}, \mathrm{Mn}$ and $\mathrm{Cd}$ increased. The exogenous $\mathrm{Cd}$ perturbs the metabolism of $\mathrm{Fe}, \mathrm{Cu}, \mathrm{Zn}, \mathrm{Mn}, \mathrm{Se}$ and $\mathrm{Cd}$. These changes may be the earliest manifestation of the toxicity of $\mathrm{Cd}$. $\mathrm{Cd}$ can cause profound changes in those metals metabolism and homeostasis.

One of the most intriguing findings in this study may be that maifanite can regulate the metals metabolism and homeostasis of rats suffering cadmium poisoning. Compared to $\mathrm{CdCl}_{2}$ group, the hippocampal levels of $\mathrm{Fe}$, Se and $\mathrm{Cu}$ in $\mathrm{CdCl}_{2}+\left(\mathrm{MF}_{\text {high }}, \mathrm{MF}_{\text {middle }}, \mathrm{MF}_{\text {low }}\right)$ group increased significantly, and those of $\mathrm{Zn}, \mathrm{Mn}$ and $\mathrm{Cd}$ decreased significantly. The larger the concentration of maifanite is, the stronger the regulating effect is.

The other most intriguing findings in this study may be that the Se level in high dose maifanite group is higher significantly than that in control group. It's well known that $\mathrm{Se}$ is an essential microelement and a constituent of many selenoproteins with antioxidant properties that bind Cd [2]. Therefore, those factors, such as size of maifanite, $\mathrm{pH}$ value, steeping time, steeping temperature, steeping solvent, heating time and heating temperature must be considered to orthogonal design when the optimum dissolved conditions were researched, in order to increase the dissolved content of Se. This may be one of the most important aspects to promote the eliminating effect on Cd toxicity of maifanite.

\section{CONCLUSION}

Cd can accumulate in rats' hippocampus, which results in the impairment of learning and memory, the decrease of SOD and GSH-Px activities, the increase of MDA and MT contents, the rise of $\mathrm{Zn}, \mathrm{Mn}$ and $\mathrm{Cd}$ levels and the decline of $\mathrm{Fe}, \mathrm{Cu}$ and Se levels. The alternation of maifanite and $\mathrm{Cd}$ by the gavage can lead to such results as improving the rats' learning and memory abilities, increasing SOD and GSH-Px activities as well as MT content, decreasing MDA content, eliminating the accumulation of $\mathrm{Cd}$ effectively, increasing the level of Se and regulating the imbalance levels of $\mathrm{Zn}, \mathrm{Mn}, \mathrm{Fe}, \mathrm{Cu}$ near to the control group level. Based on these studies, the following conclusions also can be obtained: maifanite can balance the content of trace elements in rats suffering cadmium poisoning and alleviate the toxicity of $\mathrm{Cd}$ effectively.

\section{ACKNOWLEDGEMENTS}

The authors sincerely appreciate the financial support of Natural Science Foundation of Guangxi Zhuang Autonomous Region, China (No. 2011GXNSFA018056), and Natural Science Foundation of Guangxi University of Chinese Medicine, China (No. P2010014).

\section{REFERENCES}

[1] Hideaki, S., Yasutake, A., Hirashima, T., Takamure, Y., Kitano, T., Waalkes, M.P. and Imamura, Y. (2008) Strain difference of cadmium accumulation by liver slices of inbred Wistar-Imamichi and Fischer 344 rats. Toxicology in Vitro, 22, 338-343. doi:10.1016/j.tiv.2007.09.013

[2] Lazarus, M. (2010) Cadmium and selenium interaction in mammals. Arhiv za Higijenu Rada i Toksikologiju, 61, 357-369. doi:10.2478/10004-1254-61-2010-2021

[3] Michalke, B., Halbach, S. and Nischwitz, V. (2009) JEM spotlight: Metal speciation related to neurotoxicity in humans. Journal of Environmental Monitoring, 11, 939-954. doi: $10.1039 / \mathrm{b} 817817 \mathrm{~h}$

[4] Juan, L., Zhang, P.Y., Gao, Y., Song, X.G. and Dong, J.H. (2008) Overview of maifanshi: Its Physi-chemical prop- 
erties and nutritious function in drinking water. Environmental Science \& Technology, 31, 63-66.

[5] Zhang, B.G. (2005) The Progress of pharmaceutical research on maifanite. Chinese Traditional Patent Medicine, 27, 1205-1208.

[6] Liu, Z.Y., Liu, Q., Ma, J.K. and Zhang, C.W. (1986) Study on pharmacologic action of China maifanite. Jilin Journal of Traditional Chinese Medicine, 4, 28-30.

[7] Jiang, L.F., Liao, H.L., Huang, H.M., Zhou, L.X., Li, L., Cheng, S.X. and Du, C.Z. (2013) Potential prevention and treatment of maifanite for Alzheimer's Disease based on behavior test, oxidative stress assay and trace element analysis in hippocampus of Abeta (25-35)-induced AD rats. Biological Trace Element Research, 152, 50-56. doi:10.1007/s12011-012-9590-7

[8] Kokaia, Z. and Lindvall, O. (2003) Neurogenesis after ischaemic brain insults. Current Opinion in Neurobiology, 13, 127-132. doi:10.1016/S0959-4388(03)00017-5

[9] Xu, S.Y., Bian, R.L. and Chen, X. (2002) Experimental protocols in pharmacology. 3rd Edition, People's Medical Publishing House, Beijing, 826-830.

[10] Leonard, S.S., Harris, G.K. and Shi, X.L. (2004) Metalinduced oxidative stress and signal transduction. Free Radical Biology and Medicine, 37, 1921-1942. doi:10.1016/j.freeradbiomed.2004.09.010

[11] Cousins, R.J. (1985) Absorption, transport, and hepatic metabolism of copper and zinc: Special reference to met- allothionein and ceruloplasmin. Physiological Reviews, 65, 238-309.

[12] Waalkes, M.P. and Goering, P.L. (1990) Metallothionein and other cadmium-binding proteins: Recent developments. Chemical Research in Toxicology, 3, 281-288. doi:10.1021/tx00016a001

[13] Klaassen, C.D. and Liu, J. (1998) Induction of metallothionein as an adaptive mechanism affecting the magnitude and progression of toxicological injury. Environmental Health Perspectives, 106, 297-300.

[14] Gemma, C., Vila, J., Bachstetter, A. and Bickford, P.C. (2007) Oxidative stress and the aging brain: From theory to prevention. In: Riddle, D.R., Ed., Brain Aging: Models, Methods, and Mechanisms. CRC Press, Boca Raton.

[15] Batcioglu, K., Ozturk, C., Karagozler, A. and Karatas, F. (2002) Comparison of the selenium level with GSH-Px activity in the liver of rats treated with 7,12 DMBA. Cell Biochemistry and Function, 20, 115-118. doi: $10.1002 / \mathrm{cbf} .958$

[16] Webb, M. and Cain, K. (1982) Commentary: Functions of metallothionein. Biochemical Pharmacology, 31, 137-142. doi:10.1016/0006-2952(82)90202-7

[17] Klaassen, C.D., Liu, J. and Diwan, B.A. (2009) Metallothionein protection of cadmium toxicity. Toxicology and Applied Pharmacology, 238, 215-220. doi:10.1016/j.taap.2009.03.026 